\title{
Optimization Analysis of Vibration for Grinder Spindle
}

\author{
Cheng-Chi Wang, ${ }^{1 *}$ Xin-Xiang Zhuo, ${ }^{2}$ and Yong-Quan $\mathrm{Zhu}^{2}$ \\ ${ }^{1}$ Graduate Institute of Precision Manufacturing, National Chin-Yi University of Technology, \\ No. 57, Sec. 2, Zhongshan Rd., Taiping Dist., Taichung City 411, Taiwan (R.O.C.) \\ ${ }^{2}$ Department of Mechanical Engineering, National Chin-Yi University of Technology, \\ No. 57, Sec. 2, Zhongshan Rd., Taiping Dist., Taichung City 411, Taiwan (R.O.C.)
}

(Received February 2, 2019; accepted December 13, 2019)

Keywords: chatter, Taguchi method, optimum parameters, grinding machine, spindle vibration analysis

All machines that are used for cutting operations vibrate to some degree. In this study, the vibrations generated in a surface grinding machine, which cause chatter, were investigated. Chatter leaves marks on the surface of the workpiece, and when the grinding wheel returns to these chatter marks, the chatter is often amplified in a vicious cycle and the marks become deeper. Cutting chatter can cause serious machine instability and in addition to poor product quality can result in excessive wear to the grinding wheels and even damage to the grinding machine itself. Since chatter is caused by vibration, a reduction in vibration frequency will improve cutting efficiency, lengthen the life of grinding wheels, reduce wear to the machine, improve the quality of products, and reduce cost. In this study, LabVIEW was used to extract vibration signal data, which were assembled as an MS Excel file. The Taguchi method was used for analysis to determine the main factors affecting vibration. The correctness of the optimum factors derived was verified by experiment. The factors allowed the parameters of the machine to be set to minimize vibration and chatter, improve the quality of the product, and also reduce cost.

\section{Introduction}

To speed up production, machines are often run at a high speed, large cuts are taken, and a high feed rate is used. In addition to overloading the spindles, high torques and feed rates cause more vibrations. Under such processing conditions, the surface roughness of a workpiece becomes difficult to control. The vibration generated by the cutting action itself is not difficult to handle and vibration-related studies have become very important. Most previous studies have been made with lathes and milling machines, and little work has been done with grinders. If the parameters of the experiment on grinder vibration can be appropriately adjusted, unnecessary cost can be minimized, and good surface finishes can be more easily achieved.

When a grinding wheel makes contact with a workpiece, the force transmitted to the spindle causes vibrations, which are "forced vibrations". Other vibrations that occur in the machine, not related to the force between the wheel and the workpiece, are small, and when the feeding

*Corresponding author: e-mail: wccpipn@gmail.com https://doi.org/10.18494/SAM.2020.2603 
rate is high, the vibration will be less frequent. Chatter is less likely to occur and the finish on the workpiece will be better. Surfaces will also be flatter and workpiece precision will be easier to achieve. There are many other forms of grinding process and abrasives used to grind heattreated metals, hard cutting tools, brittle materials, optical glass, and silicon wafers. However, there are many extra factors involved in wheel grinding that can affect grinding quality: these include mechanical structures, spindles, workpieces, grinding wheels, feed systems and slides, peripheral control systems, environmental factors, the forms of the grinding wheels used, workpiece materials, grinding conditions, grinding methods, and many others. Free or forced vibrations caused by whole machines, or the forces and performance of the overall mechanism will affect the ground workpiece surface. ${ }^{(1)}$ For work surfaces, surface roughness is the main criterion that represents the degree of surface unevenness of a processed workpiece. The smaller the surface roughness, the smoother the processed surface. ${ }^{(2)}$

In machine tools, two types of chatter caused by vibration can be observed; these are forced and self-excited vibrations. If obvious external vibration sources exist and the natural vibration frequency of the machine tool is consistent with the external vibration frequency, chatter can be classified as forced vibration.

However, the vibrations generated by the machine itself during the grinding operations, from the spindle, motor, and grinding wheel, and the action of grinding, are self-excited vibrations, which are the subject of this study. ${ }^{(3)}$ These self-excited vibrations can also be called chatter. During vibration, energy from the cutting process continues to be absorbed, and the occurrence of chatter is related to cutting conditions, vibration displacement, speed, and acceleration. At the same time, energy continues to be input to the cutting system, which causes a negative damping phenomenon. If the composite damping value is smaller than zero, energy is released to trigger chatter, and vibrations may become intense. ${ }^{(4)}$ Chatter occurs because the energy input is not completely absorbed by the cutting process. Excess energy is generated in the system and gradually accumulates. At a certain point, the energy is released and causes chatter. The occurrence of chatter depends on structural dynamics, the characteristics of the machine tool during the cutting process, the interaction between the workpiece and the grinding wheel, and so forth. ${ }^{(5)}$

\section{Experimental Equipment}

The Taguchi method was used as the main analytical tool in this study (see the study flow chart in Fig. 1).

\subsection{Surface grinder}

The PFG-3060AH surface grinder manufactured by Perfect Machine Co., Ltd. (see Fig. 2.) has a maximum spindle speed of $1700 \mathrm{rpm}$, precision grade ball bearings, cartridge design, and a yaw within $2 \mu \mathrm{m}$. 


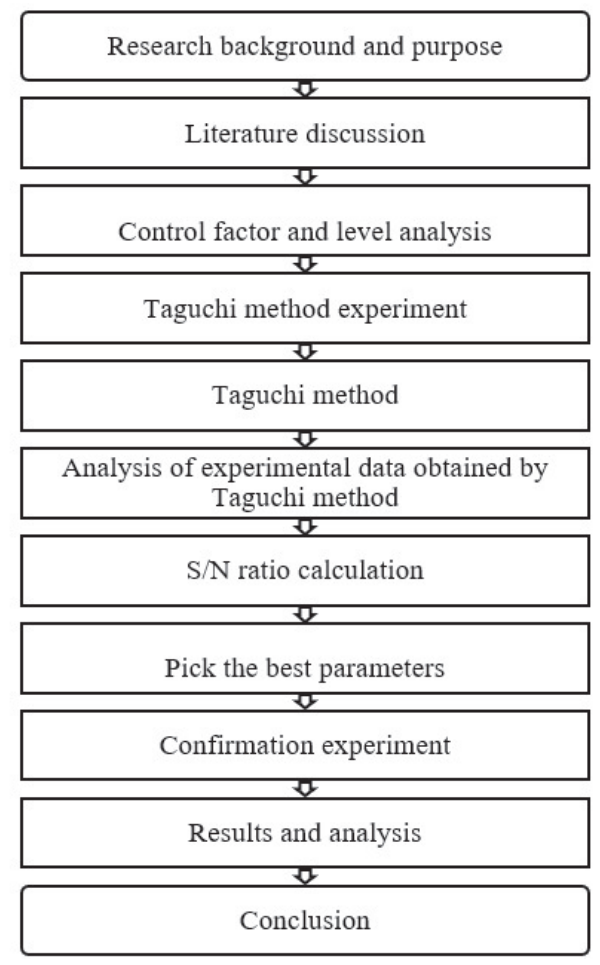

Fig. 1. Study flowchart.

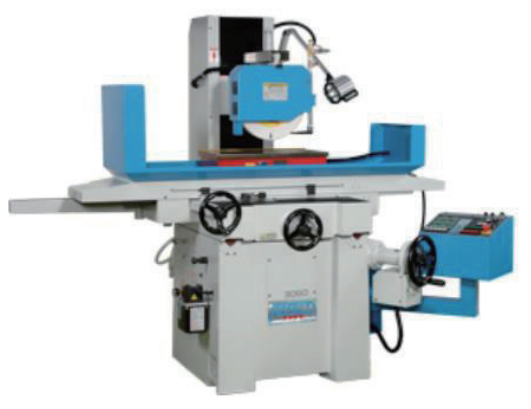

Fig. 2. (Color online) Perfect Machine grinder. ${ }^{(6)}$

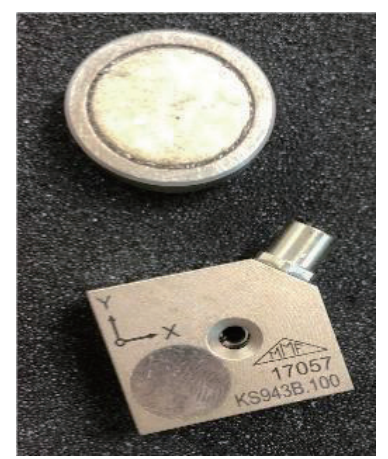

Fig. 3. (Color online) Accelerometer.

\subsection{Accelerometer}

The model KS943B.100 accelerometer used in this study is shown in Fig. 3. This piezoelectric device measures voltages generated by vibration when subject to stress. The accelerometer output requires external amplification, or an internal charge converter, to generate a voltage proportional to the frequency of vibration. Vibration signals can even be converted into amounts of material for analysis. ${ }^{(7)}$ The sensitivity specifications of the accelerometer used in this study are shown below:

$$
\begin{aligned}
& X: 102,13 \mathrm{mV} / \mathrm{g}, \\
& Y: 101,88 \mathrm{mV} / \mathrm{g}, \\
& Z: 100,32 \mathrm{mV} / \mathrm{g} .
\end{aligned}
$$

\subsection{Capture card}

The National Instruments signal acquisition module USB-9234, 4 Input, $51.2 \mathrm{KS} / \mathrm{s}, \pm 5 \mathrm{~V}$, was used to capture the vibration signals and mounted in a Model USB-9162 signal acquisition card carrier. The module was used to capture the vibration signals from the sensor, which were then collected and used as data for analysis. The card and carrier are shown in Fig. $4 .^{(8,9)}$ 


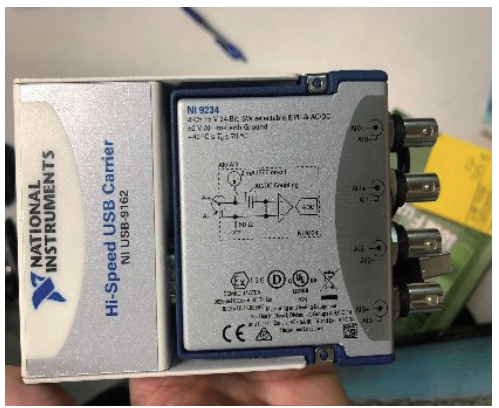

Fig. 4. (Color online) Capture card in the carrier.

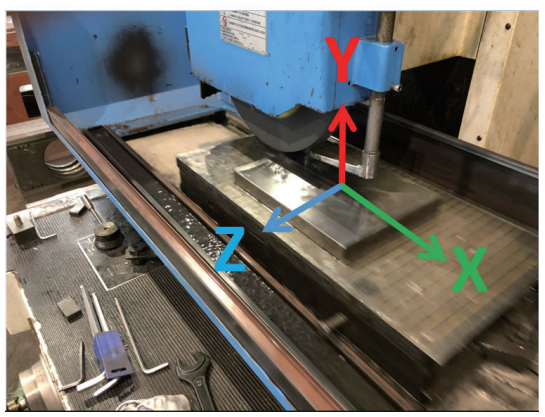

Fig. 6. (Color online) Workpiece mounted on the machine table.

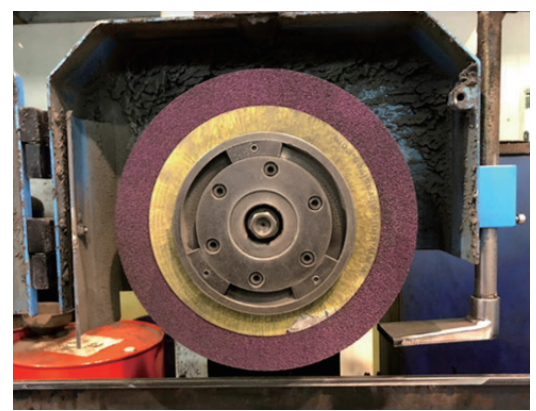

Fig. 5. (Color online) Grinding wheel.

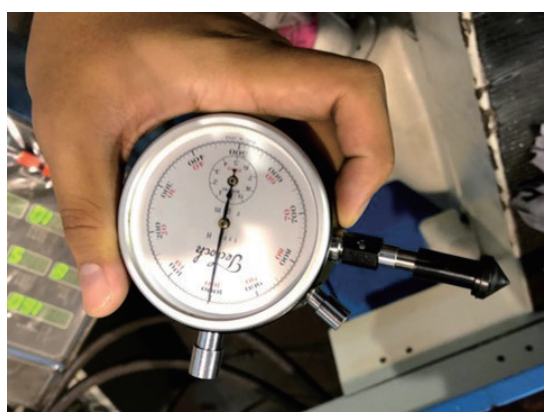

Fig. 7. (Color online) Tachometer.

\subsection{Grinding wheel}

The grinding wheels used in the experiments were 1-A-355-38-127-C-46-J-7-V (see Fig. 5).

\subsection{Material of workpiece}

The workpiece material used in these experiments was S45C medium carbon steel $(270 \times$ $210 \mathrm{~mm}^{2}$ ). For the directions defined by the experimental coordinates, refer to Fig. 6 .

\subsection{Tachometer}

The grinder only displays the spindle rotational speed in $\mathrm{Hz}$ and therefore a tachometer was used to measure the rotational speed of the grinding wheel spindle (see Fig. 7).

\section{Taguchi Method}

\subsection{Predisposing operations}

The machine used in the experiments was a PFG-3060AH surface grinder and grinding operations were carried out to find what conditions had the highest effect on cutting and product quality. 


\subsection{Instructions and introduction to Taguchi method}

Four factors were set in the Taguchi L9 orthogonal array (Table 1). These were spindle rotational speed, accelerometer location, $X$-direction cutting feed size, and $Y$-direction cutting depth. An experimental orthogonal array (see Table 2) was used to determine the required conditions and adjust the standards. To determine the standards in Factor 3 of Experiment 4, 81 measurements were obtained. The Taguchi method saves time and reduces the amount of data that needs to be analyzed. Only nine experiments were required to obtain highly accurate results suitable for industrial application.

\subsection{Signal extraction}

The accelerometer was used to detect the vibration signal and placed on three different positions as shown in Fig. 8. The measurement device was connected using NI LabVIEW

Table 1

$L_{9}$ orthogonal array.

\begin{tabular}{lllll}
\hline$L_{9}\left(3^{4}\right)$ & \multicolumn{4}{c}{ Factor column } \\
\cline { 2 - 5 } No. & A & B & C & D \\
\hline 1 & 1 & 1 & 1 & 1 \\
2 & 1 & 2 & 2 & 2 \\
3 & 1 & 3 & 3 & 3 \\
4 & 2 & 1 & 2 & 3 \\
5 & 2 & 2 & 3 & 1 \\
6 & 2 & 3 & 1 & 2 \\
7 & 3 & 1 & 3 & 2 \\
8 & 3 & 2 & 1 & 3 \\
9 & 3 & 3 & 2 & 1 \\
\hline
\end{tabular}

Factor: A is rotational speed, B is $Z$-direction feed, $\mathrm{C}$ is accelerometer location, and $\mathrm{D}$ is $X$-direction feed rate.

A. Standard: $1-1200 \mathrm{rpm}, 2-1500 \mathrm{rpm}, 3-900 \mathrm{rpm}$

B. Standard: $1-7.5 \mathrm{~mm}, 2-5.0 \mathrm{~mm}, 3-2.5 \mathrm{~mm}$

C. Standard: 1 - bottom, 2 - right, 3 - top

D. Standard: $1-42$ times, $2-35$ times, $3-28$ times
Table 2

Experimental orthogonal array.

\begin{tabular}{ccccc}
\hline & $\begin{array}{c}\text { A: } \\
\text { Rotational } \\
\text { speed } \\
(\mathrm{rpm})\end{array}$ & $\begin{array}{c}\text { B: } \\
Z \text {-direction } \\
\text { feed } \\
(\mathrm{mm})\end{array}$ & $\begin{array}{c}\text { C: } \\
\text { Accelerometer } \\
\text { location }\end{array}$ & $\begin{array}{c}\text { D: } \\
X \text {-direction } \\
\text { feed rate } \\
\text { (times/min) }\end{array}$ \\
\hline 1 & 1200 & 7.5 & Bottom & 42 \\
2 & 1200 & 5.0 & Right & 35 \\
3 & 1200 & 2.5 & Top & 28 \\
4 & 1500 & 7.5 & Right & 28 \\
5 & 1500 & 5.0 & Top & 42 \\
6 & 1500 & 2.5 & Bottom & 35 \\
7 & 900 & 7.5 & Top & 35 \\
8 & 900 & 5.0 & Bottom & 28 \\
9 & 900 & 2.5 & Right & 42 \\
\hline
\end{tabular}

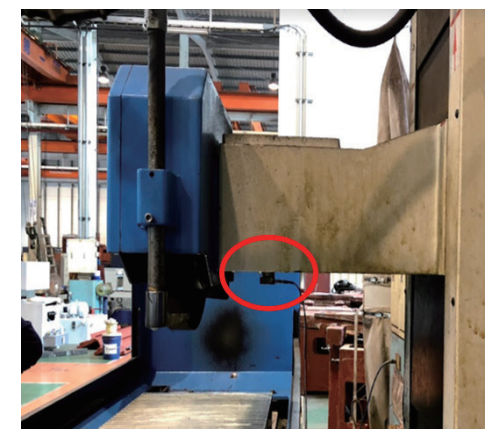

(a)

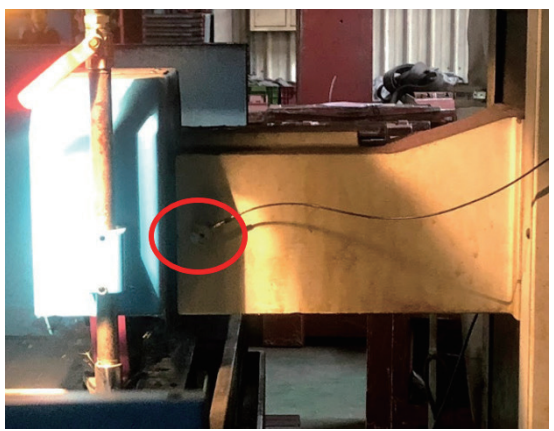

(b)

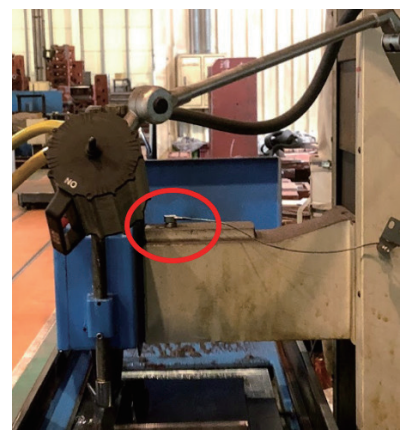

(c)

Fig. 8. (Color online) Accelerometer gauge position: (a) bottom, (b) right, and (c) top. 
2015 (32 bit) (see Fig. 9). After opening, a data acquisition (DAQ) module was used to extract and connect to the oscillator and save data to MS Excel boxes, while a loop cover was used to complete the operations.

\subsection{Root mean square (RMS) calculation}

After opening the signals extracted into Excel, the number of entries was verified, and the RMS value was calculated as

$$
M=\sqrt{\frac{\sum_{i=1}^{n} x_{i}^{2}}{n}}=\sqrt{\frac{x_{1}^{2}+x_{2}^{2}+\cdots+x_{n}^{2}}{n}} .
$$

\subsection{Standard deviation calculation}

After obtaining the RMS value, the mean of the various parameters required in the Taguchi method is shown in Eq. (2), the standard deviation in Eq. (3), and the smaller-the-better (STB) $S / N$ ratio in Eq. (4).

$$
\begin{gathered}
\bar{y}=\frac{\sum_{i=1}^{n} y_{i}}{n} \\
S=\sqrt{\frac{\sum_{i=1}^{n}\left(\bar{y}_{i}-y\right)}{n-1}} \\
S / N=-10 \log \frac{\sum_{i=1}^{n} y_{i}^{2}}{n}
\end{gathered}
$$

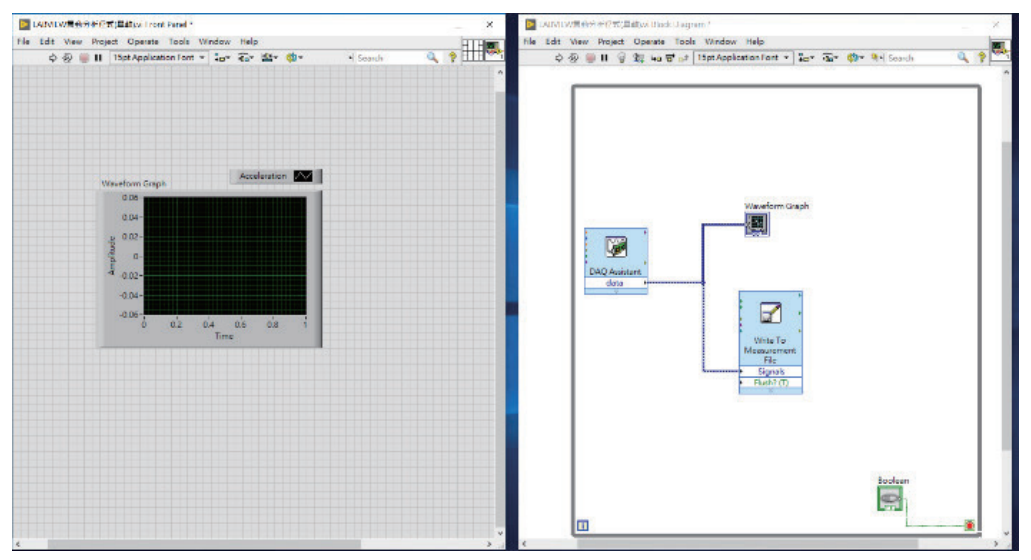

Fig. 9. (Color online) LABVIEW extraction. 


\section{Experimental Results and Analysis}

\subsection{Experimental results}

The RMS values of the nine experiments were used to calculate the mean, standard deviation, and STB values. The results are shown in Table 3 and it can be seen that the means of the 1st, 5th, and 9th experiments showed the lowest vibration frequency, the highest STB value, and the highest quality characteristics.

\subsection{Factor response chart}

After selecting, averaging, and comparing $\bar{y}$ values of various factors, a factor response chart and a factor response diagram were prepared. It was found that the vibration frequency was lowest at A1: at $1500 \mathrm{rpm}, \mathrm{B} 1: Z$-direction feed of $7.5 \mathrm{~mm}, \mathrm{C} 2$ : accelerometer located on the right, and D1: $X$-direction feed rate of 42 times/min. The results are shown in Table 4 and Fig. 10.

Table 3

Experimental results.

\begin{tabular}{cccccc}
\hline & $\begin{array}{c}\text { RMS } \\
\text { Experiment 1 }\end{array}$ & $\begin{array}{c}\text { RMS } \\
\text { Experiment } 2\end{array}$ & $\begin{array}{c}\bar{y} \\
\text { Mean }\end{array}$ & $\begin{array}{c}S \\
\text { Standard deviation }\end{array}$ & $\begin{array}{c}S / N \\
\text { STB }\end{array}$ \\
\hline 1 & 0.01201 & 0.01233 & 0.012172 & 0.00022415 & 38.2916680 \\
2 & 0.0272 & 0.02791 & 0.027557 & 0.00050558 & 31.1944728 \\
3 & 0.03936 & 0.03916 & 0.039265 & 0.00014637 & 28.1197471 \\
4 & 0.02667 & 0.02667 & 0.026672 & $2.1212 \mathrm{E}-05$ & 31.4787251 \\
5 & 0.01214 & 0.01223 & 0.012175 & $3.959 \mathrm{E}-05$ & 38.2905976 \\
6 & 0.03912 & 0.03904 & 0.039086 & $5.6568 \mathrm{E}-05$ & 28.1595709 \\
7 & 0.03978 & 0.03990 & 0.039848 & $8.4145 \mathrm{E}-05$ & 27.9917507 \\
8 & 0.03900 & 0.03972 & 0.039362 & 0.00050628 & 28.0980976 \\
9 & 0.01213 & 0.01238 & 0.012255 & 0.00017677 & 38.2332818 \\
\hline
\end{tabular}

Table 4

Factor response chart.

\begin{tabular}{lcccc}
\hline Factor & Rotational speed & $Z$-direction feed & Accelerometer location & $X$-direction feed rate \\
\hline Level 1 & 0.030488 & 0.0302021 & 0.0221616 & 0.0351 \\
Level 2 & 0.026331 & 0.0263648 & 0.0304296 & 0.035497 \\
Level 3 & 0.0259778 & 0.0262311 & 0.0302068 & 0.0122008 \\
\hline
\end{tabular}

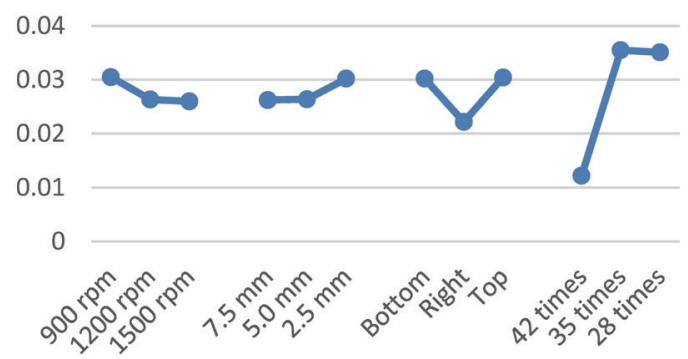

Fig. 10. (Color online) Factor response diagram. 


\subsection{Optimum parameters}

The optimum parameters were proposed and compared with the minimum value; these optimum parameters in the experiment are A1: at $1500 \mathrm{rpm}, \mathrm{B} 1: Z$-direction feed of $7.5 \mathrm{~mm}, \mathrm{C} 2$ : accelerometer located on the right, and D1: $X$-direction feed rate of 42 times $/ \mathrm{min}$.

\subsection{Verification of optimum parameters}

The experimental results were verified and the optimum parameters of the grinding machine were set. From the RMS values of the optimum parameters and the 1st, 5th, and 9th experiments, the optimization of the grinding process was proved and the accuracy of RMS for optimum parameter set was verified. The mean errors of the 1st, 5th, and 9th experiments only accounted for $1-2 \%$ as observed by comparing with the optimum parameters shown in Table 5.

\subsection{Analysis of variance}

The various factors, the error sum of square (SS) [Eqs.(5)-(7)], the degree of freedom (DOF) [Eqs. (8)-(10)], and the contribution [Eq. (11)] were obtained. ${ }^{(10)}$ The results are shown in Table 6.

$$
\begin{gathered}
S S=\frac{n \times r}{L} \sum_{k=1}^{L}\left(\bar{y}_{k}-\bar{y}_{\text {total }}\right)^{2} \\
S S_{E}=\sum_{i=1}^{n} S_{i}^{2} \times(r-1)
\end{gathered}
$$

Table 5

Comparison of optimum parameters.

\begin{tabular}{lcccc}
\hline & $\begin{array}{c}\text { Optimum } \\
\text { parameter }\end{array}$ & $\begin{array}{c}\text { No. 1 } \\
\text { (in Table 2) }\end{array}$ & $\begin{array}{c}\text { No. 5 } \\
\text { (in Table 2) }\end{array}$ & $\begin{array}{c}\text { No. 9 } \\
\text { (in Table 2) }\end{array}$ \\
\hline Rotational speed (rpm) & 1500 & 1200 & 1500 & 900 \\
$Z$-direction feed (mm) & 7.5 & 7.5 & 5.0 & 2.5 \\
Accelerometer location & Right & Bottom & Top & Right \\
$X$-direction feed rate (times/min) & 42 & 42 & 42 & 42 \\
RMS (Experiment 1) & 0.01249548 & 0.012014 & 0.012147 & 0.01213 \\
RMS (Experiment 2) & 0.012356097 & 0.012331 & 0.012203 & 0.01238 \\
$\bar{y}$ (mean) & 0.01242579 & 0.0121725 & 0.012175 & 0.012255 \\
Mean error (\%) & & 2.08 & 2.05 & 1.39 \\
\hline
\end{tabular}

Table 6

Analysis of variance.

\begin{tabular}{lccc}
\hline Factor & SS & DOF & Contribution (\%) \\
\hline Rotational speed & $7.54987 \mathrm{E}-05$ & 2 & 2.97 \\
Z-direction feed & $6.10237 \mathrm{E}-05$ & 2 & 2.40 \\
Accelerometer location & 0.000266268 & 2 & 10.50 \\
$X$-direction feed rate (times $/ \mathrm{min})$ & 0.002134514 & 2 & 84.10 \\
Error & $6.26713 \mathrm{E}-07$ & 9 & 0.02 \\
Total & 0.002537931 & 17 & 100 \\
\hline
\end{tabular}




$$
\begin{gathered}
S S_{T}=\left(\sum_{i=1}^{n} \sum_{j=1}^{r} y_{i j}^{2}\right)-n \times r \times \bar{y}_{\text {total }}^{2} \\
D O F=L-1 \\
D O F_{E}=n \times(r-1) \\
D O F_{T}=n \times r-1 \\
\text { Contribution }=\frac{S S}{S S_{T}} \times 100 \%
\end{gathered}
$$

Here, $r$ is the number of repeated experiments, $n$ is the number of measurements, and $L$ is the number of standards.

\section{Conclusion}

1. The following are the optimum parameters obtained from the experimental results: rotational speed of $1500 \mathrm{rpm}, Z$-direction feed of $7.5 \mathrm{~mm}$, accelerometer placement location on the right, and $X$-direction feed of 42 times $/ \mathrm{min}$.

2. The highest contribution was obtained from the $X$-direction feed, accounting for $84 \%$; vibration was minimized at an $X$-direction feed rate of 42 times/min and the grinder $X$-direction feed was fixed at this rate. The other parameters produced no major impact and could be adjusted.

3. The experimental data showed that the higher the $X$-direction feed rate, the lower the vibration frequency; the rotational speed and $Z$-direction feed rate had no major impact.

4. The same result was obtained using the optimum $S / N$ ratio and $\bar{y}$ mean. The conclusion was that the remaining parameters produced no major impact and could be adjusted.

\section{Acknowledgments}

The authors gratefully acknowledge the financial support provided to this study by the Ministry of Science and Technology of Taiwan under Grant Nos. MOST-108-2221-E-153-012 and MOST-108-2622-E-153-005-CC3 \& 108-2622-E-153-004-CC3.

\section{References}

1 W. Xua and Y. Wua: J. Mater. Process. Technol. 212 (2012) 927.

2 Y. Xu: Master's Thesis, National Chin-Yi University of Technology (2014).

3 Y. Wu: Master's Thesis, National Chin-Yi University of Technology (2016).

4 X. Jiayu: Master's Thesis, National Chin-Yi University of Technology (2016).

5 P. Albertelli, L. Braghieri, M. Torta, and M. Monno: Mech. Syst. Signal Process. 123 (2019) 26.

6 PERFECT MACHINE PFG-3060AH, Grinder catalog: https://www.perfectmachine.com.tw/cht/products. php? func $=$ p_detail\&p_id $=10 \& p c \_p a r e n t=17$ 
7 System Access KS943B10 KS943B100 KS943L Product catalog: http://www.systemaccess.com.tw/upload/ web/Download/MMF/KS943.pdf

8 National Instruments NI-9234: https://www.ni.com/zh-tw/shop/select/c-series-sound-and-vibration-inputmodule?modelId $=122186$

9 National Instruments USB-9162. http://www.ni.com/zh-tw/support/model.usb-9162.html

10 G. S. Peace: Taguchi Methods (Addison-Wesley, New York, 1992) p. 141.

\section{About the Authors}

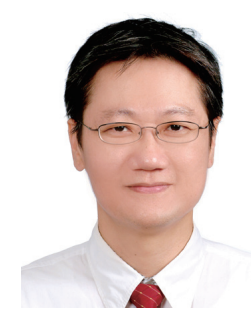

Cheng-Chi Wang serves as a distinguished professor and also the dean of the Graduate Institute of Precision Manufacturing in National Chin-Yi University of Technology in Taiwan. His current research involves intelligent machining and manufacturing, nonlinear dynamic analysis, simulation and optimization, air lubrication system and signal processing. (wcc@ncut.edu.tw)

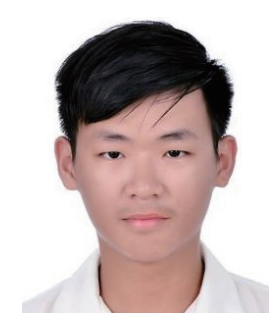

Xin-Xiang Zhuo is a graduate student of the Department of Mechanical Engineering, National Chin-Yi University of Technology. His current research involves capturing signals and data analysis.

(modest03674@gmail.com.tw)

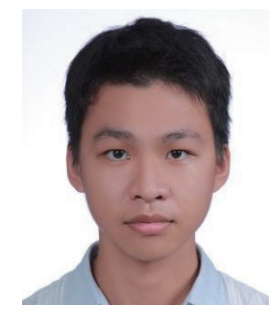

Yong-Quan Zhu is a graduate student of the Department of Mechanical Engineering, National Chin-Yi University of Technology. His current research involves chatter suppression and optimum parameters.

(anay8159@gmail.com.tw) 